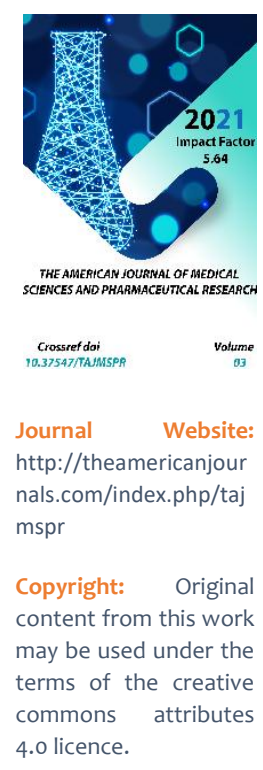

\title{
Complex Application Of Magnetic Laser Therapy And Propolis Tincture For The Prevention And Treatment Of Chronic Recurrent Aphthous Stomatitis
}

\author{
Kamola Akhtamovna Ruziyeva \\ Master's Student, Samarkand State Medical Institute, Uzbekistan \\ Zarafruz Kobil Kizi Burhonova \\ Master's Student, Samarkand State Medical Institute, Uzbekistan
}

\section{ABSTRACT}

Chronic recurrent aphthous stomatitis (stomatitis chronica aphtosa recidiva) is a chronic inflammatory disease of the oral mucosa of an infectious-allergic nature, characterized by periodic remissions and frequent exacerbations. Morphological elements on the oral mucosa are the so-called "ulcerative formations", that is, apht characterized by periodic remissions and partial exacerbations with a rash of aphtha. According to the latest publications of domestic and foreign authors, HRAS is usually considered as a polyetiological disease that plays a role in the formation and the nature of the course of the pathological process. The factor causing chronic aphthous stomatitis is staphylococcal infection, adenovirus, allergies, immune disorders, as well as diseases of organs and systems. First of all, it is a local effect aimed at reducing pain that makes it difficult to eat up to forced starvation, as well as at the speedy regeneration of the defect. Secondly, it is the regulation of the body's immunocompetent systems and a decrease in the level of bacterial allergies. In addition, the identification and treatment of background diseases with the involvement of specialists of different profiles (Lukinykh L.M., 2004; Savkina G.D., 2005; Drobotko JI.H., 2008).

\section{KEYWORDS}

Chronic recurrent aphthous stomatitis, propolis tincture, magnetic laser therapy.

\section{INTRODUCTION}

At a dental appointment in a city clinic, chronic recurrent aphthous stomatitis (HRAS) occurs mainly in the cold season, with a frequency of about 10 people per 200 people. According to 
other authors and WHO, the prevalence of HRAS among the population is $10-20 \%$, more often in schoolchildren and adolescents; with age, the incidence of the disease increases

\section{PURPOSE OF THE STUDY}

Improving the effectiveness of treatment and prevention of patients with chronic recurrent aphthous stomatitis of the oral mucosa using magnetic laser therapy and propolis tincture.

\section{Tasks:}

To give a comparative assessment of the effectiveness of prevention and treatment of patients with HRAS using magnetic laser therapy and propolis tincture according to the data of immediate and long-term results.

\section{RESEARCH MATERIALS AND METHODS}

To achieve this goal, the Samarkand dental clinic "SamDentaMedic" and the city dental clinic of the DUK conducted a comprehensive clinical and laboratory examination of 50 patients aged 20 to 60 years, including 29 men and 21 women with chronic recurrent aphthous stomatitis. The diagnosis was based on the clinical picture, laboratory methods and cytological studies. Laser therapy (LT) is actively and successfully developing as a highly effective method of treatment that has practically no contraindications and absolutely harmless. Back in the late $60 \mathrm{~s}$ of the last century, numerous studies have unequivocally proved that laser radiation is not has no side effects and long-term effects.

Laser therapy (LT) is actively and successfully developing as a highly effective method of treatment that has practically no contraindications and absolutely harmless. Back in the late $60 \mathrm{~s}$ of the last century, numerous studies have unequivocally proved that laser radiation is not has no side effects and long-term effects. Experience over than 40 years of medical use of lasers in almost all countries the world once again confirmed this [Schindl A. et al, 2000]. It is understandable, because ultra-low power of the laser source, which is thousands of times less, than the power of any lighting lamp, does not introduce anything foreign to the human body, but only restores disturbed selfregulation various physiological systems. Currently, hundreds of methods of treatment and prevention of recurrence of many diseases have been developed. Laser technology therapies are easy to implement, do not require expensive equipment, the method is effectively combined with almost all other methods treatment (both therapeutic and surgical), therefore, LT can be used in his work by any practitioner, and not only physiotherapis

\section{RESULTS AND CONCLUSIONS}

According to the obtained data of the clinical picture of laboratory data, we have developed an algorithm for the treatment of chronic recurrent aphthous stomatitis with a complex application of magnetic laser therapy and propolis tincture. With this complex therapy, the affected areas of the mucous membrane are treated with a swab moistened with propolis tincture. A low frequency magnetic laser apparatus was used as a light source. In this case, the laser dose was delivered remotely over a swab with a moistened tincture.

The number of procedures depends on the severity of the disease, the size of the lesion and the location of the lesion (in our case, aphthae and ulcers). The combined use of magnetic laser therapy and propolis tincture helps to reduce the inflammatory processes of the oral mucosa. Magnetic laser beams, penetrating deeper into the tissues of the 
body, enhance the healing effect, and also improve cell nutrition, tissue metabolism, microcirculation and vascular permeability, and the level of antioxidants increases.

According to the sources, propolis tincture has antiseptic, analgesic, antioxidant properties, helps to remove toxins from affected areas. Irradiation was performed perpendicular to the surface of the lesion. The number of procedures depends on the severity of the disease, the size of the lesion and the location of the lesion (in our case, aphthae and ulcers). The combined use of magnetic laser therapy and propolis tincture helps to reduce the inflammatory processes of the oral mucosa. Magnetic laser beams, penetrating deeper into the tissues of the body, enhance the healing effect, and also improve cell nutrition, tissue metabolism, microcirculation and vascular permeability, and the level of antioxidants increases. According to the sources, propolis tincture has antiseptic, analgesic, antioxidant properties, helps to remove toxins from affected areas. Otorhinolaryngology is one of the areas of modern health care, where laser therapy takes its rightful place. Developed by many the most modern effective techniques. The book is presented as an overview literature on the subject, as well as private methods of combined and combined laser therapy.

Non-invasive methods are also increasingly used.

$L T$, primarily with the use of pulsed lasers of red and infra-red (IR) spectra of radiation, allowing you to work without special light guide instrument. More than 30 years ago, the method of intravenous laser blood irradiation (ILBI) began to be used in laser therapy. Currently increasing the effectiveness of ILBI is associated with the introduction of the ILBI
+ UFOK technique, when exposure to laser radiation of the red spectrum alternates (length wavelength $635 \mathrm{~nm}$ ) and ultraviolet spectrum (wavelength $365 \mathrm{~nm}$, the so-called UVR of blood). Why do we pay attention to calcium ions? There are several reasons:

1. Calcium is found to the greatest extent in a specifically and nonspecifically bound state both in cells (99.9\%) and in blood (70\%) [Murray R. et al., 1993], that is, there is a possibility of a significant increase in the concentration of free calcium ions, and this process is provided more than a dozen mechanisms. Moreover, calcium is the only one of all ions, which has specialized intracellular stores for storage in a bound state - sarco- or endoplasmic reticulum.

2. The extraordinary versatility of $\mathrm{Ca}$ regulation mechanisms many physiological processes, in particular neuromuscular arousal, blood clotting, secretion processes, as well as maintaining integrity membranes and transport across membranes, many enzymatic reactions, release of hormones and neurotransmitters, intracellular action a number of hormones, etc. [Murray R. et al., 1993].

3. Therefore, the release of even a small absolute amount of these ions from the bound state leads to a significant relative increased concentration of $\mathrm{Ca2}+$ in the cytosol [Smolyaninova N.K. et al., 1990; Alexandratou E. et al., 2003].

4. The role of calcium in maintaining homeostasis is becoming more and more is known. For example, Ca 2+ -induced change in mitochondrial membrane potential and increases in intracellular level $\mathrm{pH}$ lead to an increase in ATP production and ultimately stimulate proliferation [Karu T.Y., 2000; Schaffer M. et al., 1997]. Stimulation visible light leads 
to an increase in the level of intracellular CAMP almost synchronously with the change in the concentration of intracellular $\mathrm{Ca} 2+$ in the first minutes after exposure [Daniolos A. et al., 1990], promoting thus regulation carried out by calcium pumps.

5. It is important to note that the very organization of the cell provides its homeostasis in most cases precisely through the influence of calcium on energy processes. In this case, the specific coordinating mechanism is general cellular oscillatory circuit: cytosol calcium calmodulin ( $\mathrm{CaM}$ ) - a system of cyclic nucleotides [Meerson FZ, 1984]. Also another mechanism is activated via $\mathrm{Ca} 2+-$ binding proteins: calbin din, calretinin, parvalbumin and effectors such as troponin C, CaM, synaptotagmin, S100 proteins and annexins, which are responsible for the activation $\mathrm{Ca}_{2}+$ sensitive processes in cells [John L.M. et al., 2001; Palecek J. et al., 1999].

\section{REFERENCES}

1. Diseases of the mucous membrane of the mouth and lips. Ed. L.M. Lukins. Nizhny Novgorod, 2010, pp. 89-114. 2 Abelev PI. Inflammation. // Vseros, Image. Jury. 1996. No. 6 p. 28-32,

2. Abramova EE, Vasilenko T.N. // Treatment and prevention of aphthous stomatitis. // In the book. Prevention of dental diseases. Abstracts 5 .

3. Agzamkhodzhaen S.M., Inogamov Ya.V., Tairova A, I. On the mechanism of biological and therapeutic effects of magnetic fields. // Abstracts. All-Union symposium with international participation "Magnetic-laser therapy and in medicine" - Sochi, Kuibyshev, 1991.-P.67.
4. Alexandrov M, T. Kuvekina O.A. Impact of low-energy laser radiation on MI // Mater, International, conference, "Actual problems of laser medicine and surgical endoscopy" - Moscow-Vidnoe, 1994, C 388-390.

5. Aleksandrov M.T., Prokhonchukov A.A. Lasers in dentistry // In the book; Lasers in Clinical Medicine. - M: Medicine,] 981. - S. $331-351$.

6. Antonova N.I. On the secretion of the herpes virus in chronic recurrent aphthous stomatitis of the pra cavity. D Dentistry. - 2012. - No. 1. -from. 81-82

7. Arieva G.T. Dental status, dental health and quality of life in elderly and senile patients / G.T. Arieva // Periodontology. 2013. - No. 2. - S. 63-66.

8. Wagner V.D. The importance of dental health for the patient's quality of life / V.D. Vagner, K.G. Gurevich, M.V. Peshkov, O.N. Arkharova // Problems of stomatology. - 2013. - No. 2. - P. 21.

9. Vertkin A.L. A patient with limited mobility: a critical analysis of the situation I A. L. Vertkin, V. A. Shevtsova, A. A. Sokol, O. V. Khimich // Effective pharmacotherapy. - 2014. - No. 8. - S. 1015.

10. Ivanova E.V. Improving the provision of therapeutic dental care to elderly and senile people in modern conditions: author. dis. ... Cand. honey. Sciences: 14.01.14 / E.V. Ivanova. - M., 2009 .-- 23 p.

11. Kabak D.S. Assessment of the impact of socio-demographic status on the quality of life of dental patients with comorbidity requiring conservative treatment / DS Kabak, VD Wagner // Institute of Dentistry. - 2007. - No. 1 (34). - S. 10-13.

12. Kinyabulatov A.U. Study of the problems of integration into society of people with limited mobility with severe disorders of the musculoskeletal system (wheelchair users) / A.U. Kinyabulatov, Z.A. Nurgaliev 
The American Journal of Medical Sciences and Pharmaceutical Research

(ISSN - 2689-1026)

Published: June 30, 2021 | Pages: 127-130

Doi: https://doi.org/10.37547/TAJMSPR/Volume03Issue06-20

\author{
IMPACT FACTOR \\ 2021: 5.64 \\ OCLC - 1121105510
}

// Youth in science: new arguments.

Collection of scientific papers $\mathrm{V}$ - 